Revista de Humanidades, 38 (2019). p. 65-84. ISSN 1130-5029

\title{
El arte digital y su relación con la violencia de género
}

\section{Digital art and its relationship to gender violence}

\author{
Adriana-Graciela Segura-Mariño \\ Pontificia Universidad Católica del Ecuador (Ecuador) \\ smag@pucesd.edu.ec \\ Andrés García-Umaña \\ Pontificia Universidad Católica del Ecuador (Ecuador) \\ guea@pucesd.edu.ec
}

Fecha de recepción: 01/06/2018

Fecha de aceptación: 23/09/2019

\section{Resumen}

Los medios digitales permiten una comunicación más directa que los tradicionales. Los activistas pueden optimizar su labor al encontrar nuevas formas de difundir mensajes, construidos en formatos audiovisuales con un componente estratégico para contrarrestar problemas sociales, como la violencia de género. Con esta investigación se pretende determinar si el arte digital es una herramienta persuasiva contra este problema en el entorno online. Esto se resolvió a través de dos etapas: la primera consta de una revisión bibliográfica; la segunda consiste en el análisis de contenidos sobre el desarrollo de las acciones online de artivistas que luchan contra la violencia de género, y sobre los proyectos influyentes (según ONU Mujeres y el Festival Iberoamericano de la Publicidad - FIAP) que se han realizado en distintos contextos geográficos, identificando su difusión en plataformas de comunicación, los formatos, contenidos, audiencia y engagement. Se detectó que no se aprovecha estratégicamente la comunicación 2.0; los pocos artivistas que tienen presencia en Internet se limitan a convocar a acciones offline; si bien los proyectos influyentes rompen estereotipos y promueven la participación de la audiencia, no se dirigen a los adolescentes, que son quienes más utilizan Internet. El trabajo multidisciplinario es clave para diseñar soportes altamente visuales y persuasivos.

Palabras clave: Comunicación; Audiovisual; Arte; Violencia de género; Activismo. 


\begin{abstract}
Digital media allow a more direct communication than traditional media. Activists can optimize their work finding new ways to spread messages, which are built in audiovisual formats with a strategic component to counteract social problems, such as gender violence. The objective of this research is to determine if digital art is a persuasive tool against this problem in the online environment. This was resolved through two stages: the first one consists of a bibliographic review; the second one consists of a content analysis on the development of online actions by artivists who work against violence of gender, and on the influential projects (according to UN Women and the Ibero-American Advertising Festival - FIAP) that have been carried out in different geographical contexts, identifying their diffusion in communication platforms, the formats, contents, audience and engagement. It was detected that 2.0 communication is not used strategically; the few artivists with presence on the Internet only call for offline actions; Although influential projects break stereotypes and promote audience participation, they do not target adolescents, the ones who most use the Internet. Multidisciplinary work is key to designing highly visual and persuasive supports.
\end{abstract}

Keywords: Communication; Audiovisual; Art; Gender violence; Activism.

\title{
1. INTRODUGCIÓN Y ESTADO DE LA GUESTIÓN
}

Internet ha generado la aparición de nuevos medios de comunicación social. A este ciberespacio han migrado los tradicionales para aprovechar ventajas como la interactividad entre usuarios o el uso de formatos diversos como la comunicación audiovisual y multimedia. La inmediatez es otra ventaja que ofrecen los medios digitales (García, Del Hoyo, \& Fernández, 2014). Quienes conforman la audiencia pueden comentar, compartir, seleccionar y valorar los contenidos que reciben; aunque no pueden alterarlos, pueden producir nuevos contenidos, adoptando así el rol de prosumidores, acrónimo de productor-consumidor (Cebrián, 2009; García \& Valdivia, 2014; Berrocal, Campos, \& Redondo, 2014).

Se prevé que la comunicación 2.0 ha impactado en los hábitos y psicología de los usuarios, especialmente de quienes están en la adolescencia, periodo en el cual se define la personalidad mediante las relaciones sociales (Oberst, Chamarro, \& Renau, 2016; Bandura \& Walters, 1990). A estos usuarios se les conoce como «nativos digitales»y son quienes pasan más tiempo frente a las pantallas (Aguaded \& Caldeiro, 2013; Prensky, 2001). Tienen entre 10 y 15 años de edad (Colás, 2013). Comienzan el uso de Internet desde niños ya sea por influencia personal, social, familiar o por la gratificación percibida de contenidos. Cuando están en el bachillerato lo usan por temas relacionados con su educación. Utilizan los medios online para comunicarse, entretenerse, aprender y en algunos casos participar en la realidad ciudadana, política o cultural (González, Becerra, \& Yanez, 2016). Como se trata de una comunicación horizontal, interactiva y recíproca, se les facilita aprovechar la tecnología para conocer, opinar y participar en temas públicos, sociales y globales 


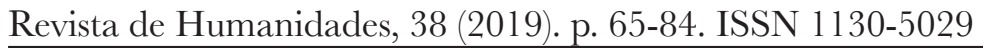

(Gozálvez, 2011), así como en temas solidarios o cívicos (García, Del Hoyo \& Fernández, 2014). Sin embargo esto no es constante, ya que se ha detectado que los adolescentes están menos predispuestos que los adultos a usar los medios digitales para temas de interés social; prefieren no involucrarse en reclamos políticos a pesar de tener competencias para ello (Grijalva \& Moreno, 2017).

Sin embargo, el uso incorrecto de Internet podría afectar el desarrollo social de los nativos digitales (Lloria, 2019). Cuando el uso es excesivo se minimiza el tiempo que comparten fuera de línea con sus familiares o amigos, se genera una sensación de soledad o depresión (Lee, 2009; García-Umaña, 2017) y corren el riesgo de no discernir entre contenidos buenos y malos (Herrero \& Serrano, 2006). Respecto a su autopresentación, se preocupan por cumplir estereotipos de belleza y de género que asimilan del entorno audiovisual. Los hombres publican imágenes para proyectar independencia y fuerza, mientras que las mujeres buscan proyectar protección, belleza e intimidad; quieren ser admiradas mostrando escotes, piernas, labios, espalda u hombros (Tortajada, Araüna, \& Martínez, 2013). Aunque los chicos no consideran que su identidad esté marcada por estereotipos de masculinidad en adultos respecto a los roles de género, esa sensación aumenta conforme crecen; las chicas mientras más femeninas se autoperciben, menor sensación de bienestar psicológico podrían tener (Oberst, Chamarro, \& Renau, 2016). Los adolescentes de Colombia y de España utilizan Facebook para socializar con sus amigos y demostrar originalidad; con ese afán sobreexponen su intimidad a través de imágenes, compartiendo datos personales o aceptando como amigos a personas que no conocen en la realidad, aún sabiendo que esto es peligroso (Almansa, 2013).

Existen casos de ciberviolencia de género en adolescentes, que quizá llega a ser el reflejo de una realidad física y psicológica. La mayoría de agresores son hombres, mientras que la mayoría de víctimas son mujeres, aunque con poca diferencia. Los chicos reconocen que suelen difundir imágenes con contenido sexual o sugerente, sin consentimiento de las chicas (Álvarez, Barreiro, \& Núñez, 2017). El dispositivo que más utilizan en estos contextos es el teléfono móvil inteligente (Durán \& Martínez, 2015; García-Umaña, 2017; Lloria, 2019).

El problema se podría estar originando en el entorno offline, en el cual la violencia de género adopta distintas formas según el marco geográfico y cultural. Hay mujeres que desde su nacimiento no son totalmente bienvenidas, porque se considera que no aportan económicamente, creen que su rol de adultas es servir al hombre, tienen menos oportunidades laborales para ascender o son acosadas sexualmente para mantener su trabajo. Muchas no son conscientes de que sufren un cuadro de violencia, para ellas es normal ser las únicas responsables de cumplir con roles domésticos, porque eso han percibido en sus estructuras sociales y en los medios de comunicación. Otras no se atreven a denunciar, porque los agresores suelen ser sus parejas (Quiñones, 2010). La consecuencia más grave que estaría produciendo la violencia de género es el femicidio (Monleón, 2012). 
Respecto a la lucha contra la violencia, en Estados Unidos las mujeres dieron a conocer los malos tratos en el siglo XV y reclamaron el sufragio universal a finales del siglo XIX; el feminismo se oficializó en países norteamericanos en las décadas de los setenta y ochenta del siglo XX y en los latinos en la década de los noventa (Quiñones, 2010). Hay que destacar que los activistas son los gestores del cambio, son quienes promueven el empoderamiento social, superando el miedo y desafiando al poder para reformar las normas establecidas, motivados por la desconfianza en los gobernantes respecto a su manera de proceder ante problemas sociales. El cambio se da como resultado de una comunicación masiva, independiente, horizontal, interactiva, multidireccional y global; en ese sentido los medios sociales en Internet cumplen un papel importante (Castells, 2012).

El artivismo, acrónimo de «arte» $\mathrm{y}$ «activismo», aplicado por movimientos feministas, se inició en los años sesenta del siglo pasado, a través de vídeos y performance, tomando el cuerpo humano como soporte del mensaje. Su objetivo principal es concientizar a la sociedad para ejecutar acciones estratégicas y consolidar cambios políticos. Los protagonistas son colectivos o artistas independientes, tanto como los espectadores. Originalmente el artivismo tuvo lugar en espacios urbanos (Ortega, 2015).

A inicios de los setenta ya se luchaba por la igualdad de género dentro del campo del arte y del activismo político (Monleón, 2012). Un ejemplo de artivistas es el grupo «Guerrilla Girls» de 1984, quienes propusieron códigos visuales nuevos en la época, cuestionando la estética sobre el género y el sexo, mediante parodias y sobre todo pretendiendo la participación del público (Ortega, 2015). Desde la década de los noventa se ampliaron las manifestaciones artísticas contra la violencia de género desde distintos campos como las artes plásticas, cine y vídeo, poesía y periodismo alternativo (Salvador, 2013).

Varios ejemplos de artivismo han sido referentes en distintos contextos. En Estados Unidos, el performance «Cut piece» de Yoko Ono, quien utilizó como recurso la visibilización de la violencia. En Latinoamérica, el vídeoarte de la artista guatemalteca Regina José Galindo, el cual fue grabado mientras le realizaban una himenoplastia, intervención quirúrgica que muchas mujeres de su país se realizan porque sufren la presión social de llegar vírgenes al matrimonio. Luego, con el propósito de que el artivismo ganara espacio en los medios de comunicación, artistas como Jenny Holzer o Martha Rosler fusionaron lo urbano con los medios sociales, utilizando las pantallas spectacolor en Times Square (Monleón, 2012). En América Central y el Caribe español, la feminista de Costa Rica, Emilia Prieto, realizó xilografías que se publicaron en la revista «Repertorio Americano», utilizó como recurso el cuerpo femenino, porque para ella es el espacio dominado por una sociedad que exige curvas, maquillaje e hijos. La mexicana Natalia Eguiluz, a través de pinturas en acrílico sobre madera, propuso el mensaje «¿Cuántas más?» cuestionando a las instituciones políticas sobre cuántas mujeres más tienen que 


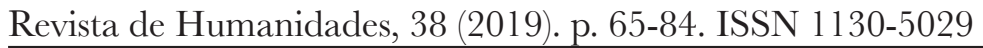

morir para que se tomen medidas. La artista puertorriqueña Carmen Mojica propuso la instalación de fotografía interactiva sobre la violencia doméstica para que los espectadores comprendieran el sufrimiento de las mujeres en sus roles de amas de casa (Quiñones, 2010).

Debido a que existe relación directa entre el consumo de medios y los comportamientos violentos de la audiencia, se intenta que a través de los mismos medios se fomente el cambio (García \& Valdivia, 2014). La convergencia entre tecnología, activismo y arte es clave para desarticular estereotipos de género que fomentan la violencia (Lloria, 2014; Ballester, 2012). Internet supone reforzar el artivismo, pues permite diferentes formas de visualización, producción y constitución (Ortega, 2015). Las redes sociales son reconocidas como entornos que posibilitan el intercambio de ideas y la democracia (Ringrose \& Barajas, 2011). Las cuales, bien canalizadas podrían ser un potencial recurso para el fortalecimiento de procesos de construcción e inclusión social (Colás, 2013).

Los primeros trabajos de artivismo en Internet se dieron en 1994 y desde entonces se han resuelto con más creatividad problemas de comunicación visual, porque la Red se ha consolidado como el espacio de difusión para llevar acciones en el contexto offline (Baigorri, 2004). Se podría configurar en un medio de comunicación para el empoderamiento ciberfeminista a través del videoarte y performance, que son las técnicas menos machistas y más utilizadas con las que se pretende romper estereotipos de género (Ballester, 2012). El arte y las tecnologías en general se han convertido en las herramientas permanentes de feministas para abordar temas contra la violencia de género. Algunos ejemplos son las Plataformas Universitarias como "Canadian Women's Studies On-Line», «Center for Gender Studies» y «Women's Studies». Otros casos iberoamericanos incluyen a «Mujeres en Red», «Red Feminista de Organizaciones contra la violencia de género», «Asociación de Mujeres Separadas y Divorciadas», «Fundación Mujeres», «Federación de Mujeres Progresistas», «Comisión contra los malos tratos», «Mujeres en las Artes Visuales» y «Arte Contra Violencia de Género» (Monleón, 2012).

En los formatos de vídeos que se publican en las redes digitales, los mensajes suelen ser más informativos que críticos, terminan con un imperativo para luchar contra la violencia y para denunciarla. Son pocos los casos en los que las estructuras son reflexivas e interrogativas, es decir dejan al espectador en una posición pasiva; por lo tanto los comentarios son mínimos e incluso restringidos. En lugar de fomentar la imagen de mujeres independientes que no se dejan manipular, las representan como víctimas, como subordinadas (Puente, García \& Romero, 2014).

En realidad, el artivismo más que preocuparse de temas estéticos procura conseguir resultados, cambios políticos (Ortega, $r \cdot 10)$, pero esto no le debe restar valor a la comunicación visual, porque se ha detectado que lo más importante del proceso comunicativo es el impacto que generan los mensajes en los receptores, por lo tanto el poder de las imágenes es primordial, ya que al ser recursos visuales 
refuerzan las emociones al conectar contenido y forma (Castells, 2012). Además, está demostrado que la cultura visual moldea la personalidad, los valores relacionados con el sexo y los estereotipos tradicionales de masculinidad y feminidad (Monleón, 2012). Es decir, que la conducta y valores de los nativos digitales pueden verse modificados, ya que con las redes sociales y los múltiples dispositivos que existen para utilizarlas, están expuestos a mucha más información que antes, porque disponen de varias pantallas además del televisor, por ejemplo los videojuegos, el ordenador, las tablets y los teléfonos móviles (Aguaded \& Caldeiro, 2013).

La publicación de noticias sobre casos de violencia es el formato que utilizan algunas organizaciones políticas y educativas que se preocupan por contrarrestarla, sin embargo las campañas audiovisuales pueden tener dos efectos: «insensibilización» e «imitación». La insensibilización se da cuando las noticias se transmiten tanto, que se pierde el asombro y se ve a la violencia como algo normal. La imitación se da cuando las personas que ya son propensas a ser violentas, encuentran un referente que les incita a ser violentos (Brändle, Cárdaba \& Ruiz, 2011). Por lo tanto, hablar mucho de violencia puede banalizarla en lugar de contrarrestarla (Salvador, 2013). De hecho, los índices de violencia de género se mantienen o aumentan a pesar de las campañas de comunicación que se realizan (Brändle, Cárdaba \& Ruiz, 2011).

Sin duda, se debe encontrar nuevas estrategias para empoderar a las audiencias respecto al uso responsable de los medios digitales (Grijalva \& Moreno, 2017). Es fundamental disminuir la posibilidad de que los adolescentes se transformen en agresores, formándolos a tiempo en valores con enfoque en el respeto a la intimidad de las personas (Álvarez, Barreiro, \& Núñez, 2017).

Son las instituciones educativas para adolescentes las encargadas de iniciar el proceso de enseñanza sobre lecturas de mensajes audiovisuales y posteriormente de educarles para que produzcan mensajes, pero antes hay que formar a los educadores (Herrero \& Serrano, 2006). La alfabetización mediática digital debe contemplar y analizar las fuentes que toman como referencia los nativos digitales para su autopresentación en redes sociales y cómo éstas perjudican su identidad. Los medios digitales deberían ser aprovechados para fomentar la no aceptación a estereotipos de género, basándose en prácticas de reflexión (Tortajada, Araüna, \& Martínez, 2013). Las instituciones educativas deben establecer espacios de análisis en Internet para detectar si existen contenidos sociales que promueven los derechos civiles básicos, la igualdad de las personas o el rechazo a la violencia (Gozálvez, 2011).

Es importante poder aprovechar el potencial de las nuevas tecnologías para luchar contra la violencia de género, innovando en la aplicación de las artes digitales; la labor debe ser permanente (Lloria, 2019; Monleón, 2012). Los mensajes deben producirse mediante contenidos con textos más cortos, formatos multimedia y principalmente con información visual (Dahlgren, 2011). Pero sobre todo, no se puede dejar la responsabilidad sólo a los padres o a las instituciones educativas, debe ser un trabajo compartido en la sociedad (Aguaded \& Caldeiro, 2013). Lo ideal es 


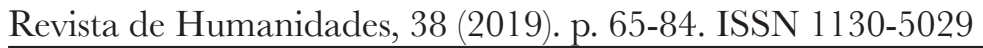

que sean propuestas locales, según la realidad de cada región. También es ideal el trabajo multidisciplinario, esto ha sido demostrado en países iberoamericanos como España o Argentina (Salvador, 2013).

El enfoque de la participación de nativos digitales podría ser la clave para reforzar el artivismo en cibermedios, porque utilizan estos espacios a diario y poseen vastos conocimientos sobre sus usos. Además las competencias digitales para emitir y recibir información textual, sonora y visual mejora la conectividad entre entornos online y offline, a la vez que refuerzan la efectividad de la participación de los adolescentes (Dahlgren, 2011).

Hay aún pocas investigaciones sobre el papel de la comunicación 2.0 como responsable de la violencia así como responsable de la lucha contra ella; por eso cabe preguntarse si ésta puede combatirla, más que fortalecerla y promoverla (García \& Valdivia, 2014). Han existido casos de ciberactivismo que han conseguido cambios positivos, pero se ha reconocido que aquello no se logra desde la tecnología sino desde el compromiso de la sociedad civil (Betancourt, 2011). Por lo tanto, la cuestión principal sobre el artivismo en Internet es determinar su efectividad, identificando qué impacto genera en las plataformas digitales de comunicación (Baigorri, 2004). Considerando que es necesario que los usuarios se vuelvan más autónomos y más críticos como consumidores y productores de mensajes en los medios digitales, hay que identificar qué contenidos reciben (Aguaded \& Caldeiro, 2013). Se debería descubrir qué recursos adicionales existen para fomentar más compromiso en los adolescentes (García, Del Hoyo, \& Fernández, 2014).

Con el interés de dar respuesta a estos planteamientos, el objetivo principal de esta investigación es determinar si el arte digital en la comunicación 2.0 realmente combate la violencia de género en el entorno online. Para ello se analizó cómo se desarrollan las acciones online de artivistas registrados en la plataforma web Arte Contra Violencia de Género - ACVG y también se analizó el contenido de proyectos influyentes que se han realizado en distintos contextos geográficos, con el propósito de identificar si han sido difundidos en plataformas digitales de comunicación y otras variables como formatos, contenidos, audiencia y «engagement» $\mathrm{o}$ «compromiso». Para no sesgar la información, se consideraron proyectos influyentes a aquellos encontrados en dos fuentes oficiales, por una parte los ganadores de los premios «De Igual a Igual a la Publicidad no Sexista 2017» que otorga la Organización de las Naciones Unidas que promueve la igualdad de género y el empoderamiento de las mujeres (ONU Mujeres) y por otra parte los ganadores del año 2017 en el Festival Iberoamericano de la Publicidad - FIAP.

\section{MATERIALES Y MÉTODOS}

Considerando que el artivismo aplicado en medios digitales para luchar contra la violencia de género tiene pocos años de investigación, porque es un 
tema relativamente nuevo (Quiñones, 2010), se empleó una metodología ad hoc para realizar análisis de contenido, como parte de un diseño de tipo descriptivo y transversal. Los datos se recopilaron en matrices durante octubre, noviembre y diciembre de 2017. Los resultados se ajustaron en el paquete estadístico SPSS para proceder a la realización de análisis univariados y cruce de variables con mayor precisión, tanto cuantitativas como cualitativas.

En el estudio se incluyeron los siguientes sujetos y objetos de investigación. Primero se indagó sobre los 105 artivistas y colectivos de Iberoamérica registrados en la plataforma web ACVG (Moleón, 2012), con el objetivo de definir cómo se desarrollan sus acciones en Internet. Las variables analizadas son: sexo, país de origen, presencia en medios online, uso de medios, seguidores, formato, contenido, audiencia y engagement. Posteriormente se observaron 265 proyectos de comunicación que se consideraron influyentes por ser ganadores de los premios otorgados por ONU Mujeres y FIAP en el año 2017, de ellos se seleccionaron los artes digitales que buscan contrarrestar el problema de la violencia de género y se excluyeron los que se repetían por ser ganadores en más de una categoría, de ese modo quedaron en total 23 artes (4 de ONU Mujeres y 19 de FIAP). Esto con el objetivo de analizar su contenido e impacto en los medios digitales. Las variables estudiadas son: país de origen, medios de difusión, formatos, contenidos, efecto viral y engagement.

Cabe mencionar que el interés por complementar la investigación incluyendo proyectos ganadores de ONU Mujeres y FIAP 2017 se debe especialmente a que es importante analizar no sólo el trabajo de artistas independientes, sino también el de marcas referentes, ya que el objetivo del activismo y del artivismo es conseguir cambios, mas no limitar el campo de acción.

Con los resultados obtenidos se pretende responder la cuestión principal de esta investigación: ¿Es el arte digital una herramienta persuasiva contra la violencia de género en la comunicación 2.0?

\section{ANÁLISIS Y RESULTADOS}

\subsection{Artivistas en el entorno online}

La plataforma web Arte Contra Violencia de Género - ACVG mantiene un registro de 105 artivistas y colectivos de Iberoamérica. Sobre ellos, a través de una búsqueda en exploradores de Internet, se averiguó un conjunto de datos que se registraron en una matriz y posteriormente en el software SPSS, con el objetivo de definir cómo se desarrollan sus acciones en Internet. Se analizaron las siguientes variables: sexo (hombres, mujeres), país de origen, presencia en medios online (sitio web, blog, página en Facebook), uso de medios (difusión de activismo offline, ciberactivismo, ambos), número de seguidores, formatos (imagen, audio, 
texto, vídeo), contenido (si refuerzan los estereotipos de género y si fomentan la participación), audiencia (hombres, mujeres, niños, adolescentes, adultos) y engagement (reacciones, comentarios y compartidos).

De los 105 artivistas y colectivos, 98 son mujeres y 7 son hombres (Figura 1). Si bien de 30 personas no se pudo encontrar datos sobre su país de origen, la mayoría son de España (32) y México (17); después están los de Argentina (9), Colombia (5), Cuba (5) y Costa Rica (4); la minoría son de Guatemala (2), Perú (2), Brasil (2) y Chile (2); y sólo hay 1 de Puerto Rico, 1 de Uruguay y 1 de Ecuador. Se suman a la lista 1 de Finlandia y 1 de Francia, que aunque no nacieron en países de la región, sus actividades las desarrollan allí (Figura 2).

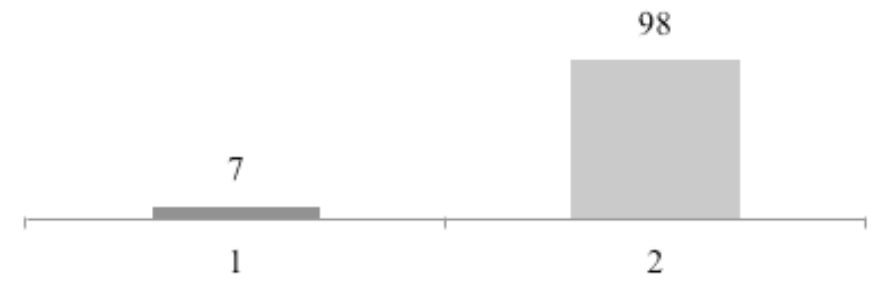

Figura 1. Sexo

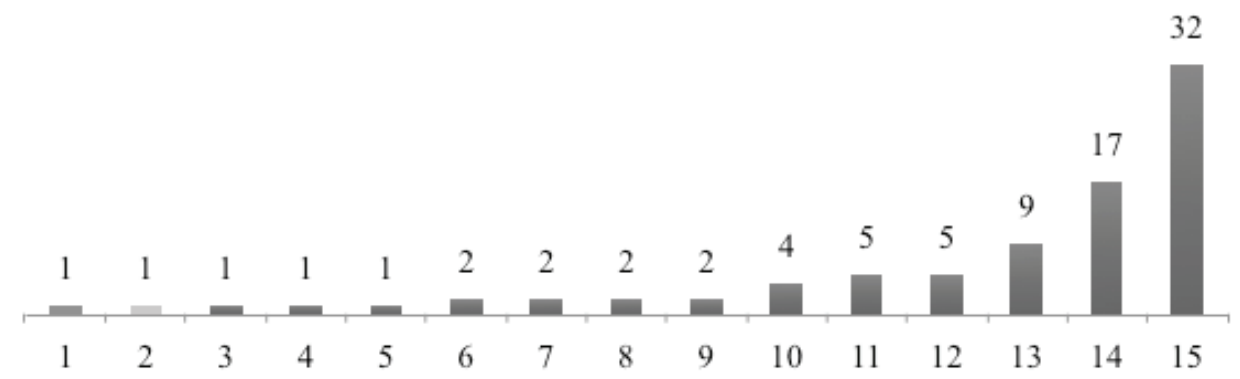

Figura 2. País de origen.

De los 105 artivistas, 53 tienen presencia en Internet mediante plataformas oficiales propias. De ellos, 42 personas tienen un sólo medio y 11 tienen dos medios; de los 42 que tienen un solo medio: 27 poseen sitio web, 13 poseen blog y 2 poseen página en Facebook. De los 11 que tienen dos canales: 10 poseen sitio web y página en Facebook y 1 tiene blog y página en Facebook (Tabla 1). De los 53 artivistas que tienen presencia en el entorno online a través de medios oficiales y propios, la mayoría son de España (18) y de México (10). 
Tabla 1. Número y tipo de medios.

\begin{tabular}{ccccccc} 
& \multicolumn{5}{c}{ Medio } \\
\cline { 2 - 6 } $\begin{array}{c}\text { Número de } \\
\text { medios }\end{array}$ & Web & Blog & Facebook & $\begin{array}{c}\text { Blog y } \\
\text { Facebook }\end{array}$ & $\begin{array}{c}\text { Web y } \\
\text { Facebook }\end{array}$ & Total \\
\hline 1 & 27 & 13 & 2 & 0 & 0 & 42 \\
2 & 0 & 0 & 0 & 1 & 10 & 11 \\
Total & 27 & 13 & 2 & 1 & 10 & 53 \\
\hline
\end{tabular}

Es decir, que en total hay 13 artivistas que tienen página oficial en Facebook. De quienes el número de seguidores tiene un recorrido de 5 a 10009 con una mediana de 982. Se detectó que este medio lo utilizan de manera restringida, ya que 6 artistas lo usan tanto para difundir activismo offline como para ciberactivismo, 5 no tienen participación activa en esta red (no han realizado publicaciones hace más de 3 meses) y 2 lo usan exclusivamente para difundir activismo offline.

Las publicaciones de los 6 artistas que sí realizan ciberactivismo son desarrolladas en formatos de imagen (con predominio de ilustraciones más que de fotografías), ningún artivista genera audio, texto o vídeo a través de este medio social que permite la interactividad con la audiencia.

Los contenidos refuerzan los estereotipos de género, ya que el recurso visual para protestar es la mujer dominada, maltratada o sumisa. Por otra parte, los contenidos son de carácter pasivo y unilateral, es decir que no fomentan la participación de los usuarios de Facebook.

Todas las publicaciones que realizan se dirigen a mujeres adultas, mas no a jóvenes. Consiguen escaso engagement (menos de 70 reacciones positivas, menos de 50 comentarios y menos de 50 veces compartidas). Como es evidente, quienes han conseguido «engagement» son los $\wedge$ artistas que mantienen actividad en Facebook, independientemente del fin para el que lo utilicen (difundir activismo offline o ciberactivismo).

\subsection{Arte digital contra la violencia de género}

ONU Mujeres y FIAP son dos referentes importantes en Iberoamérica tanto en el campo de la lucha contra la violencia de género como en el campo de la creación audiovisual y del arte digital aplicado a la publicidad. Se observaron los 265 artes digitales ganadores para seleccionar aquellos que tratan el tema de la violencia de género y excluir los que se repetían por haber clasificado en más de una categoría, quedando un total de 23 piezas «4 de ONU Mujeres y 19 de FIAP». Sobre ellos, se indagó sobre variables mencionadas por los autores citados, las mismas que se desarrollan a continuación. Los datos se registraron en una matriz para posteriormente 
ingresarlos al software SPSS, con el objetivo de analizar su contenido e impacto en los medios digitales.

La mayoría de artes que tratan el problema social son los realizados en España (8) y Argentina (6), después están los realizados en Perú (3), Brasil (2) y México (2). Sólo hay 1 de Colombia y 1 de República Dominicana (Figura 3).

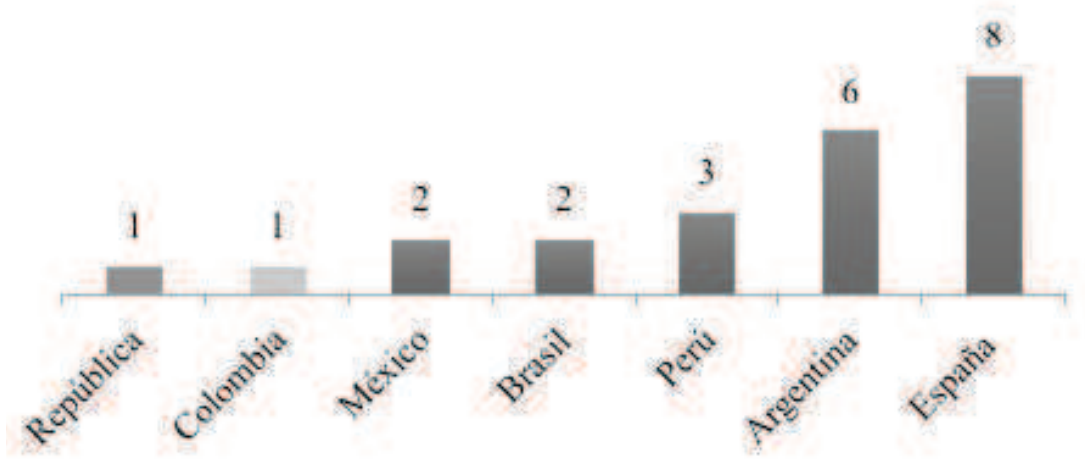

Figura 3. País de producción.

En lo que respecta a medios, se detectó si han sido difundidos en plataformas propias de las marcas anunciantes, en medios tradicionales (radio, prensa, televisión) o a través de crossmedia (digitales y tradicionales). Se encontró que 14 aplicaron crossmedia, 6 se difundieron en televisión y 3 en plataformas digitales propias (Figura 4).

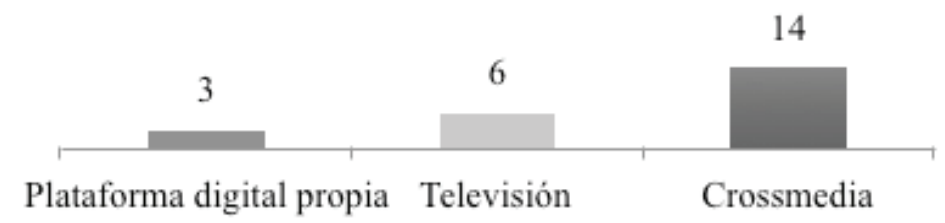

Figura 4. Medios de difusión.

Sobre los formatos, 14 artes se desarrollaron en vídeo, 3 en comportamientos activistas, 2 en apps, 2 en audio, 1 en canción y 1 en obra de teatro.

En cuanto a los contenidos, se determinó si reforzaban o no los estereotipos de género y si promovían o no la participación de la audiencia. Sólo 1 reforzaba los estereotipos y 22 no; mientras que 17 promovían la participación de la audiencia y 6 no. De aquellos 22 que no reforzaban los estereotipos, la mayoría promovía la participación de los usuarios, mientras que el único que reforzaba los estereotipos 
no promovía la participación en redes, se trata de un arte desarrollado en España, país donde más luchan contra este problema en Internet. Es necesario mencionar que de aquellos que no refuerzan los estereotipos, la mayoría son de España (7) y de Argentina (6).

Sobre la audiencia se reconoció a qué personas se dirigen los mensajes (hombres, mujeres, niños, adolescentes, adultos). 14 se dirigen a hombres y mujeres adultos, 6 se dirigen a todos, 2 sólo a hombres adultos y 1 sólo a mujeres adultas (Figura 5). Es decir que nuevamente se ve una escasez de mensajes dirigidos a jóvenes.

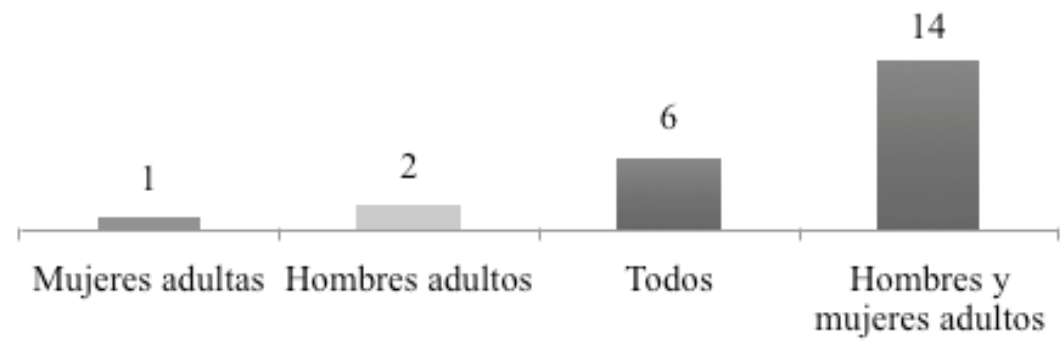

Figura 5. Audiencia.

Se buscó si los productos de comunicación tuvieron efecto viral en Internet. De los 23 sólo 3 no se convirtieron en virales. La mayoría de países que consiguieron viralizar son España (6) y Argentina (5). El engagement se pudo medir de aquellos artes de los cuales se disponía de una o más de la siguiente información: vistas, reacciones y compartidos. Las cifras no son totales, sino individuales: las vistas tienen un recorrido de 2700 a 48000000 con una mediana de 1258343 , las reacciones tienen un recorrido de 2 a 700000000 con una mediana de 42 000, los comentarios tienen un recorrido de 0 a un 1000000 con una mediana de $345 \mathrm{y}$ de las veces que fueron compartidos se tienen datos sólo de dos proyectos analizados, 900 y 700000 compartidos.

\section{DISGUSIÓN Y CONGLUSIONES}

El índice de casos de ciberviolencia en adolescentes han sido dominados lastimosamente por el género femenino (Álvarez, Barreiro, \& Núñez, 2017), de acuerdo a la intervención realizada al grupo total de artivistas de la investigación, se constató que el $93 \%$ son mujeres con un mínimo porcentaje masculino de $6.7 \%$, por lo cual se estima una falta de compromiso y participación igualitaria con respecto a la persuasión sobre violencia de género en los medios sociales. No obstante, se debería analizar la aplicación tradicional de artivismo para aseverarlo firmemente.

El análisis iberoamericano permitido por la plataforma de Arte Contra Violencia de Género - ACVG demuestra muy poca participación de activistas latinos e incluso 


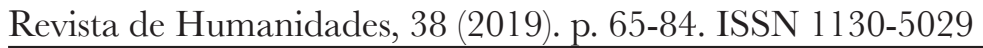

marca la ausencia de otros (Monleón, 2012); la plataforma agrupa activistas de forma libre y voluntaria, su inclusión permitirá la identificación y participación activa, sin embargo su expansión estará determinada por la promoción y reconocimiento de personas o grupos activistas.

La estructura comunicativa implantada por la Red de Internet, posiblemente ha facilitado el uso singular de navegación y permite determinar el alcance deseado. El resultado del estudio determina que el $100 \%$ de artivistas están registrados en la plataforma ACVG pero solo el $49,5 \%$ tienen presencia medianamente activa en Internet realizado mediante redes sociales propias, desaprovechando la amplia posibilidad de alcance y proyección de las herramientas de comunicación 2.0. Se podría considerar que el aumento del nivel de alfabetización mediática digital en los artivistas consolidaría su presencia en los medios digitales. Ahora bien, del universo total el 12,4\% ha creado página de Facebook en una media de seguidores considerablemente baja, se estima que su uso es muy restringido debido a que cinco de ellos o lo han dejado de usar o en su mayoría convocan acciones fuera del entorno online, limitando la interacción social (González, Becerra, \& Yanez, 2016; Aguaded y Caldeiro, 2013).

Existe una diferencia marcada entre cómo desarrollan la comunicación online los artivistas y los anunciantes corporativos que ganaron premios de ONU Mujeres y FIAP. Mientras los artivistas refuerzan los estereotipos que fomentan la violencia de género, los anunciantes buscan romperlos, desean empoderar a las mujeres, proyectándolas como independientes, en un entorno de igualdad. Esto es importante porque evita efectos de insensibilización y de imitación que mencionaban Brändle, Cárdaba, \& Ruiz (2011). Se ha detectado que los adolescentes están menos predispuestos que los adultos a usar los medios digitales para temas de interés social; prefieren no involucrarse en reclamos políticos a pesar de tener competencias para ello (Grijalva \& Moreno, 2017).

Se debe generar arte digital con contenidos para nuevas audiencias, ya que no se puede luchar contra la violencia de género si sólo los esfuerzos se dirigen a mujeres adultas. Es necesario prevenir el problema y en este sentido los adolescentes son importantes, no sólo porque están en una etapa donde definen su personalidad (Lloria, 2019; Oberst, Chamarro, \& Renau, 2016; Bandura \& Walters, 1990), sino porque son quienes más utilizan estos medios y sobre todo porque está demostrado que la cultura visual moldea la personalidad, los valores relacionados con el sexo y los estereotipos tradicionales de masculinidad y feminidad (Monleón, 2012). Por lo cual, el grupo de nativos digitales son quienes pasan más tiempo frente a las pantallas digitales (Aguaded \& Caldeiro, 2013; Prensky, 2001).

El éxito de los esfuerzos online depende en gran medida del uso de multicanales, del efecto viral que pueden tener los mensajes y que la comunicación 2.0 hace posible. De hecho, son los artes digitales difundidos en Internet los que han conseguido 
interés por parte de los usuarios. En cuanto a formatos también existe una diferencia marcada entre el trabajo de los artivistas y los anunciantes corporativos, ya que mientras los primeros se limitan a trabajar con imágenes, los segundos proponen nuevos formatos como aplicaciones móviles, canciones difundidas en Internet y ciberactivismo a través de vídeos.

Es alentador que la mayoría de proyectos ganadores en ONU Mujeres y FIAP hayan tenido un efecto viral y engagement elevado, en este sentido los países que aún están ausentes en el ciberespacio tienen grandes referentes para aplicar o incluso replicar estrategias de éxito. La comunicación digital impacta los hábitos y la psicología del usuario, por tanto se estima que el Artivismo mantiene una oportunidad relevante y quizá única, para lograr un alcance masificado y la difusión viral de ideales (Colás, 2013; Aguaded y Caldeiro, 2013). Sin embargo, se destaca el poco uso de plataformas virtuales, considerando que su expansión activista se ha realizado de manera tradicional u offline.

Los activistas son los gestores del cambio, su intervención social a través de todos los medios debe ser constante y el engagement debe aumentar significativamente. La redirección digital de sus contenidos debe ir enfocada a los adolescentes de una manera más directa, pues son ellos los que podrán ser influenciados positivamente debido a su constancia en el uso de medios digitales.

El apoyo al arte con sentido social es una tarea pendiente en Latinoamérica y parte del mundo, junto a la difusión por medios digitales se podría considerar una herramienta persuasiva muy significativa. Aunque los sitios web oficiales de ONU Mujeres y FIAP son referentes importantes en la región iberoamericana, actualmente el arte digital no sostiene una presencia influyente contra la violencia de género.

\section{REFERENCIAS BIBLIOGRÁFICAS}

Aguaded, J. I., \& Caldeiro, M. C. (2013). Dimensión axiológica de la competencia mediática. Repercusión de las pantallas en el colectivo adolescente de Lugo [Axiological dimension media literacy. The screens impact in adolescent of Lugo]. Enseñanza \& Teaching, 1(31), 77-90. https://goo.gl/522fw4

Almansa-Martínez, A., Fonseca, O., \& Castillo, A. (2013). Redes sociales y jóvenes. Uso de Facebook en la juventud colombiana y española. [Social Networks and Young People. Comparative Study of Facebook between Colombia and Spain]. Comunicar, 20(40), 127-135. https://doi.org/10.3916/C40-2013-03-03

Álvarez-García, D., Barreiro-Collazo, A., \& Núñez, J. C. ( $\uparrow \cdot 1 \vee)$. Cyberaggression among Adolescents: Prevalence and Gender Differences. [Ciberagresión entre adolescentes: prevalencia y diferencias de género]. Comunicar, 25(50), 89-97. https://doi.org/10.3916/C50-2017-08

Baigorri, L. (2004). Recapitulando: modelos de artivismo (1994-2003). Artnodes: revista de arte, ciencia y tecnología, 6(3), 1-12. https://goo.gl/Krx8NC 


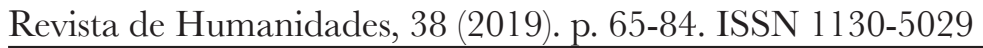

Ballester, I. B. (2012). Confluencias feministas entre arte y tecnología. Arte y políticas de identidad, 6(1), 161-176. https://goo.gl/WC63gM

Bandura, A. y Walters, R. (1990). Aprendizaje Social y Desarrollo de la personalidad. Madrid: Alianza editorial.

Berrocal, S., Campos, E. \& Redondo, M. (2014). Media prosumers in political communication: Politainment on YouTube. [Prosumidores mediáticos en la comunicación política: el «politainment» en YouTube]. Comunicar, 43, 65-72. https://doi.org/10.3916/C43-2014-06

Betancourt, V. (2011). Ciberactivismo: ¿Utopía o posibilidad de resistencia y transformación en la era de la sociedad desinformada de la información?. Chasqui: Revista Latinoamericana de Comunicación, 0(116), 94-97. https://goo.gl/jQq3zB

Brändle, G., Martín, M. A., \& Ruiz, J. A. (2011). Riesgo de aparición del efecto boomerang en las comunicaciones contra la violencia. [The Risk of Emergence of Boomerang Effect in Communication against Violence]. Comunicar, 19(37). https://doi.org/10.3916/C37-2011-03-08

Castells, M. (2012). Redes de indignación y esperanza. Madrid: Alianza Editorial.

Cebrián, M. (2009). Comunicación interactiva en los cibermedios. [Interactive Communication in the Cybermedia]. Comunicar, 17(33), 15-24. https://doi. org/10.3916/c33-2009-02-001

Colás, P., González, T., \& De Pablos, J. (2013). Juventud y redes sociales: Motivaciones y usos preferentes. [Young People and Social Networks: Motivations and Preferred Uses]. Comunicar, 20(40), 15-23. https://doi.org/10.3916/C40-2013-02-01

Dahlgren, P. (2011). Jóvenes y participación política. Los medios de la red y la cultura cívica. Telos: Revista de pensamiento, sociedad y tecnología, 1(89), 1-11. https:// goo.gl/ukbFx 7

Durán, M., \& Martínez-Pecino, R. (2015). Ciberacoso mediante teléfono móvil e Internet en las relaciones de noviazgo entre jóvenes. [Cyberbullying trough Mobile Phone and the Internet in Dating Relationships among Youth People]. Comunicar, 22(44). https://doi.org/10.3916/C44-2015-17

García, M.C. \& Valdivia, A. (2014). Media Prosumers. Participatory Culture of Audiences and Media Responsibility. [Prosumidores mediáticos. Cultura participativa de las audiencias y responsabilidad de los medios]. Comunicar, 43, 10-13. https://doi. org/10.3916/C43-2014-a2

García-Galera, M. C., Del-Hoyo-Hurtado, M., \& Fernández-Muñoz, C. (2014). Jóvenes comprometidos en la Red: el papel de las redes sociales en la participación social activa. [Engaged Youth in Internet. The Role of Social Networks in Social Active Participation]. Comunicar, 21(43). https://doi.org/10.3916/C43-2014-03

García-Umaña, A. (2017). Impacto social y educativo del comportamiento mediático digital contemporáneo: Nomofobia, causas y consecuencias. Dilemas Contemporáneos, 1(35), 1-21. https://goo.gl/8D6JpK 
El arte digital y su relación con la violencia de género - A.G. Segura-Mariño y otros

González-Lizárraga, M. G., Becerra, M.T., \& Yanez, M. B. (2016). Ciberactivismo: nueva forma de participación para estudiantes universitarios. [Cyberactivism: A new form of participation for University Students]. Comunicar, 24(46), 47-54. https://doi.org/10.3916/C46-2016-05

Gozálvez, V. (2011). Educación para la ciudadanía democrática en la cultura digital. [Education for Democratic Citizenship in a Digital Culture]. Comunicar, 18(36), 131-138. https://doi.org/10.3916/C36-2011-03-04

Grijalva-Verdugo, A. A., \& Moreno-Candil, D. (2017). Empoderamiento social en contextos violentos mexicanos mediante la competencia mediática. [Social Empowerment in Mexican Violent Contexts through Media Competence]. Comunicar, 25(53), 29-38. https://doi.org/10.3916/C532017-03

Lee, S. J. (2009). Online communication and adolescent social ties: Who benefits more from Internet use?. Journal of Computer-Mediated Communication, 14(3), 509531. https://doi.org/10.1111/j.1083-6101.2009.01451.x

Lloria, P. (2014). Crímenes y castigos. Miradas del Derecho penal a través del arte y la cultura. Tirant lo Blanch: España.

Lloria, P. (2019). La violencia de control como violencia de género. ReCrim2019. https://www.uv.es/iccp/recrim/recrim19/recrim19d01.pdf

Lloria, P. (2019). La violencia sobre la mujer en el siglo XXI: sistemas de protección e influencia de las tecnologías de la información y la comunicación en su diseño. La ley penal: revista de derecho penal, procesal y penitenciario, 138.

Monleón, P. M. (2012). Arte y tecnología frente a la violencia de género: [ACVG www. artecontraviolenciadegenero. org]. Arte y Políticas de Identidad, 6, 177194. https://goo.gl/nUYbG3

Moreno, H. I. M., \& García, S. J. A. (2006). Nuevas pantallas: otras formas de comunicar en el siglo XXI. Educatio siglo XXI, 24, 123-150. https://goo.gl/TxRnWv

Núñez, P. S., Rubira, G. R., \& Fernández, R. D. (2014). La construcción del sujeto víctima de la violencia de género en Youtube como acto performativo: estudio del activismo online desde el análisis multimodal. Cuadernos Kóre, 1(8), 179-199. https://goo.gl/WUXkSg

Oberst, U., Chamarro, A., \& Renau, V. (2016). Estereotipos de género 2.0: Autorepresentaciones de adolescentes en Facebook. [Gender Stereotypes 2.0: Selfrepresentations of Adolescents on Facebook]. Comunicar, 24(48), 81-89. http:// dx.doi.org/10.3916/C48-2016-08

Ortega, V. (2015). El Artivismo como acción estratégica de nuevas narrativas artísticopolíticas. Calle 14: revista de investigación en el campo del arte, 10(15). https:// goo.g1/2SKRV8

Prensky, M. (2001). Digital Natives, Digital Immigrants. On the Horizon, 9(5), 1-6. http://goo.gl/93tth3 
Revista de Humanidades, 38 (2019). p. 65-84. ISSN 1130-5029

Quiñones, O. E. (2010). Este cuerpo es mío: Manifestaciones culturales contemporáneas en torno a la violencia machista en América Central y el Caribe español. Arte y políticas de identidad, 2(1), 123-140. https://goo.gl/yH1SLm

Ringrose, J., \& Barajas, K. E. (2011). Gendered risks and opportunities? Exploring teen girls' digitized sexual identities in postfeminist media contexts. International Journal of Media \& Cultural Politics, 7(2), 121-138. https://goo.gl/WcgL5Y

Rizo, G. M., \& Romeu, V. A. (2013). Comunicación, Cultura y Violencia. In Rizo, G. M. (Eds.), Comunicación, Intersubjetividad y Violencia. Algunas reflexiones en torno a la debilitación de las relaciones comunicativas en entornos violentos (pp.23-32). Bellaterra: Institut de la Comunicació, Universitat Autònoma de Barcelona.

Rizo, G. M., \& Romeu, V. A. (2013). Comunicación, Cultura y Violencia. In Pech, S. C. (Eds.) Arte y Violencia: Apuntes en torno a una estética de lo peor y sus derivas en el arte activismo (pp. 45-58). Bellaterra: Institut de la Comunicació, Universitat Autònoma de Barcelona.

Tortajada, I., Araüna, N., \& Martínez, I. J. (2013). Estereotipos publicitarios y representaciones de género en las redes sociales. [Advertising Stereotypes and Gender Representation in Social Networking Sites]. Comunicar, 21(41), 177-186. https://doi.org/10.3916/C41-2013-17 